\title{
Methodology for measuring car traction parameters
}

\author{
Bronisław Kolator ${ }^{1, *}$, and Michat Janulin ${ }^{1}$ \\ ${ }^{1}$ University of Warmia and Mazury in Olsztyn, 10-719 Olsztyn, Poland
}

\begin{abstract}
The article presents methodology for testing the traction parameters of the vehicle on the laboratory stand. The tests have been carried out using MAHA LPS 3000 chassis dynamometer. Power output can be measured in two ways, at steady state or during acceleration. Both have benefits as well as drawbacks. Car manufacturers are required to use steady state tests for certification of power output. It has an advantage as it is a well defined test that is easy to repeat and verify. The problem with results measured during acceleration is that the acceleration itself has a considerable effect on the result.
\end{abstract}

\section{Introduction}

Engine Performance, declared by the automotive manufacturer, is related to a specific test procedure where the engine is separately mounted and tested in an engine dynamometer. Chassis dynamometer testing analyses the main factors affecting a vehicle in order to closely reproduce them in a testing facility. It provides complete guidance on how these tests should be performed, including the requirements affecting the test cells themselves so that they can be fully optimized [1].

SAE Recommended Practice J1540 specifies test procedures to map transmission efficiency and parasitic losses in a manual transmission. The procedure comprises two parts. The first compares input and output torque over a range of speed to determine efficiency. The second measures parasitic losses at zero input torque over a range of speed. As specified in J1540, efficiency of transmissions is routinely measured on a test-stand under steady torque and speed. While such testing is useful to compare different transmissions, it is unclear whether the "in-use" efficiency of a given transmission is the same as that measured on the stand [2].

Kołodziej et al presents way of conduct of automobiles' diagnostics testing on uniaxial chasses dynamometer [5]. Chassis dynamometers are very popular to run some quick tests for installed power and check out the chassis and drivetrain [4]. The identification of traction and speed characteristics as well as of fuel economy of motor vehicles in road conditions has been presented Sergey N Krivtsov et al [3].

Rototest Research Institute defines Powertrain Performance as the performance available to the wheels (measured at the wheel hubs). A simple description is the engine performance minus the drivetrain losses [6].

This has historically always been the way to do it and has the benefit of a controlled environment during the test. However, the modern cars of today have increased the integration of the whole powertrain to a degree where it has made it in practice impossible to test an engine separately.

\section{Test method and measuring}

Power output can be measured in two ways, at steady state or during acceleration. Both have benefits as well as drawbacks. Car manufacturers are required to use steady state tests

* Corresponding author: bronislaw.kolator@uwm.edu.pl 
for certification of power output. It has an advantage as it is a well defined test that is easy to repeat and verify.

The simplest way of testing is to let the engine / car accelerate against a fixed inertia load. Simple in one way most often means drawbacks in other ways. In this case it has numerous drawbacks, which affects the results. Also you are limited to just one type of test. A more demanding test for the dyno is to accelerate against the road load. Then the dyno has to simulate running on the road. This can be good when tuning a specific car. However the results will be affected by the vehicle set-up. Changing the weight of the car will produce different power readings even if it is the same engine.

The chassis dynamometer LPS 3000 is available in various versions for performance testing of cars [7]. Depending on the version, wheel power from $260 \mathrm{~kW}$ to $520 \mathrm{~kW}$ with a max. test speed of $260 \mathrm{~km} / \mathrm{h}$ can be tested. The dyno load simulation is done with an eddycurrent brake. The LPS 3000 enables engine power measurements to be made on cars with Otto and diesel engines. Testing of four wheel drive vehicles is possible if the LPS 3000 is equipped with the appropriate roller set and the corresponding control electronics. Measurement programs, this dynamometer provides an exact simulation of defined road load conditions. Fuel consumption measurement and exhaust analysis, as well as serial monitoring of vehicles can be carried out. The following operation modes can be selected for conducting the various measurement tasks (Fig. 1):

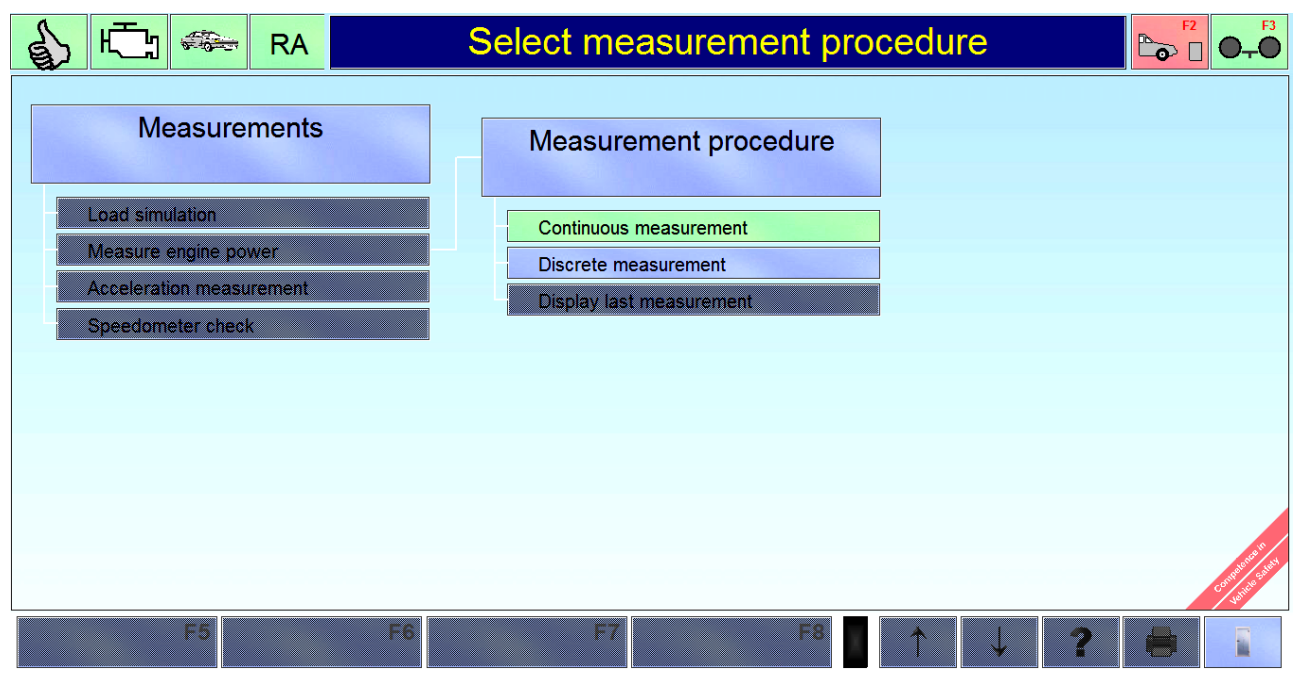

Fig. 1. MAHA dynamometer monitor view for select measurement procedure test.

- Load Simulation - The user can pre-select from various load conditions which make possible the determination of e.g. a specific engine diagnosis or vehicle climbing power. Depending upon need, various load conditions can be simulated such as constant traction, a constant speed, a constant RPM or a driving simulation.

- Measure Engine Power - Use this menu item to determine the vehicle's engine power (continuous and discrete measurement).

- Extrapolation of the Engine Power - Extrapolation of the engine power based on DIN 70020, EWG 80/1269, ISO 1585, JIS D 1001, SAE J 1349.

- Flexibility Test - The engine flexibility can be checked using this menu item. Once the flexibility test has been called up the vehicle weight and road load must be entered as in the road load simulation test.

- Speedometer Test - The vehicle's speedometer can be tested using this menu item. The speed can be tested as well. 
- Road Load Adaption - Various dyno coefficients can be determined using this menu item. The iterative coefficient adaption can be done based on ECE or SAE J2264 standard.

- Lug-Down Test - Use this menu item to do a diesel exhaust measurement under full load.

The max. power is determined during a continous measurement and the engine power is calculated according to DIN 70020, EWG 80/1269, ISO 1585, SAE J1349, depending on which setting has been selected in category "Power Correction". The curves for wheel, drag and engine performance are displayed graphically. If air pressure and temperature have been taken into consideration (measured) the engine performance is displayed as standard performance.

Discrete power measurement makes it possible to approach pre-defined points and hold them for a specified time as a function of the speed or RPM (Fig. 2). These target points must be set before testing begins. The Start- and End speeds or RPM as well as the test increments and hold time are entered by the inspector. Hold time is defined as the length of time which the pre-set approached RPM and/or speed is held constant. The hold time assures a stable test point so that for example enough time is left for a fuel consumption test to be done. The Start-Hold time eases the regulation procedure. More accurate test results are supplied for turbo-charged engines, whose charger often has a delayed reaction.

\begin{tabular}{|l|l|r|r|}
\hline Measurement over engine RPM & Rarameter for discrete power measurement & Measurement via speed \\
\hline Start-RPM [rom] & 1680 \\
\hline End-RPM [rpm] & 4680 \\
\hline RPM step increments [rpm] & 300 \\
\hline Hold time [s] & 3 \\
\hline Additional hold time before start of measurement [s] & 2 \\
\hline
\end{tabular}

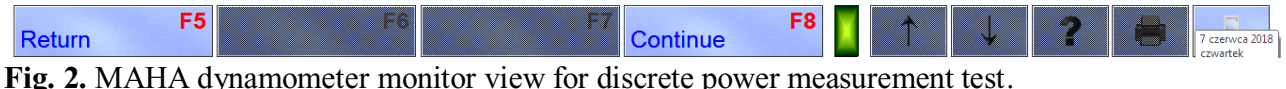

You are free to use colour illustrations for the online version of the proceedings but any print version will be printed in black and white unless special arrangements have been made with the conference organiser. Please check whether or not this is the case. If the print version will be black and white only, you should check your figure captions carefully and remove any reference to colour in the illustration and text. In addition, some colour figures will degrade or suffer loss of information when converted to black and white, and this should be taken into account when preparing them. These test instructions serve to set out the basic conditions for wheel power measurement in writing and are to provide a basis for reproducible measurements [8].

\section{Test results}

The problem with results measured during acceleration is that the acceleration itself has a considerable effect on the result. It is therefore important that the rate of acceleration is 
defined and controlled within tight tolerances (Fig. 3). Only then can the test be repeated and verified.

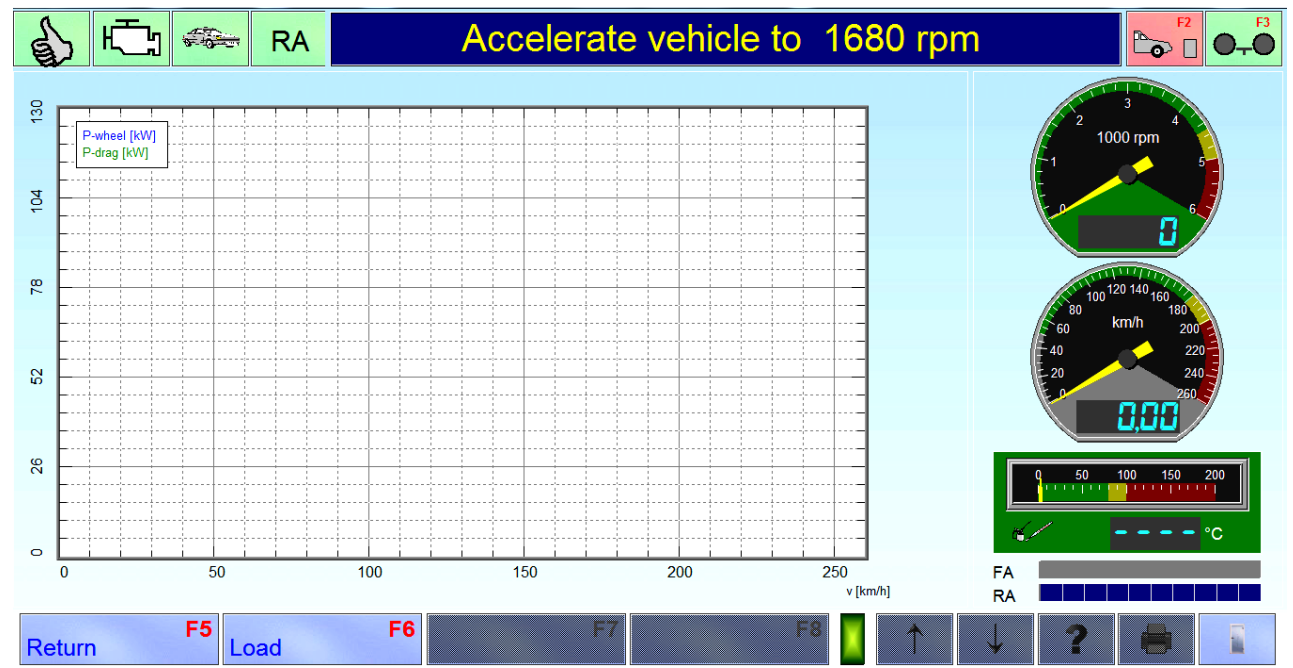

Fig. 3. MAHA dynamometer monitor view for accelerate vehicle.

This is a comparison of steady state vs acceleration at a steady rate. The acceleration is started at $1680 \mathrm{rpm}$ and stopped at $4680 \mathrm{rpm}$. The main difference is caused by the inertia of the drive train but also the fact that the engine is running in a different way when it is accelerating compared to steady state.

The influence is even more evident in the following figures. Engine power continuous measurement (Fig. 4) and discrete measurement (Fig.5). As the steady rate increases full torque is reached later and the torque available is decreased. The inertia of the drive train is reducing the available torque directly related to the acceleration rate. However it is obvious that the difference is related to other variables as well, especially if you compare the fastest steady rate to the others. Sample waveforms of the recorded values have been presented in Table 1 continuous measurement and in Table 2 discrete measurement.

Table 1. Parameters values of the engine during continuous measurement tests on the chassis dynamometer.

Measurement date: 14.05.2018 (8:59)

Measurement data table

\begin{tabular}{|c|c|c|c|c|c|}
\hline $\begin{array}{c}\mathrm{n} \\
{[\mathrm{rpm}]}\end{array}$ & $\begin{array}{c}\mathrm{v} \\
{[\mathrm{km} / \mathrm{h}]}\end{array}$ & $\begin{array}{l}P_{\text {Wheel }} \\
{[\mathrm{kW}]}\end{array}$ & $\begin{array}{l}P_{\text {Eng }} \\
{[\mathrm{kW}]}\end{array}$ & $\begin{array}{l}\mathrm{P}_{\text {Norm }} \\
{[\mathrm{kW}]}\end{array}$ & $\begin{array}{c}\mathrm{M}_{\mathrm{Morm}} \\
{[\mathrm{Nm}]}\end{array}$ \\
\hline 1800 & 53,9 & 4,3 & 9,8 & 9,8 & 519 \\
\hline 2100 & 62,9 & 12,4 & 18,9 & 18,9 & 85,9 \\
\hline 2400 & 71,8 & 18,9 & 26,6 & 26,5 & 105,5 \\
\hline 2700 & 80,8 & 26,0 & 34,9 & 34,8 & 1 \\
\hline 3000 & $89, \overline{8}$ & 38,0 & $4 \overline{8}, 1$ & 48,0 & $152, \overline{9}$ \\
\hline 3300 & 98,8 & 40,7 & 52,2 & 52,1 & ! \\
\hline 3600 & 107,7 & $42, \overline{7}$ & $5 \overline{5}, 7$ & 55,6 & 147,4 \\
\hline 3900 & 116,7 & 44,4 & 59,0 & 58,9 & ل144,1 \\
\hline 4200 & 125,7 & 45,3 & 61,8 & 61,7 & 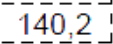 \\
\hline 4500 & 134,7 & 44,8 & 63,2 & 63,1 & 133,9 \\
\hline
\end{tabular}




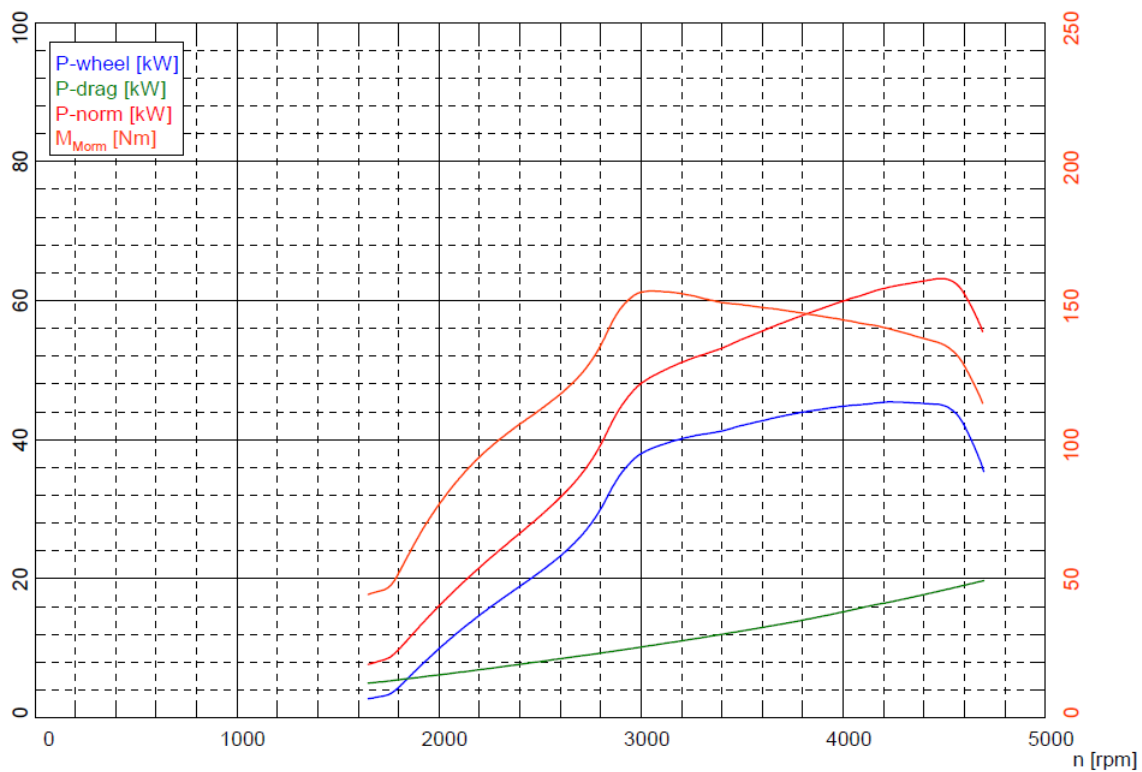

Max. attained RPM

$4695 \mathrm{rpm} / 140,6 \mathrm{~km} / \mathrm{h}$

Fig. 4. Characteristics of power and torque for engine continuous measurement.

Table 2. Parameters values of the engine during discrete measurement tests on the chassis dynamometer.

Measurement date: $14.05 .2018(9: 13)$

\section{Measurement data table}

\begin{tabular}{|c|c|c|c|c|c|}
\hline $\begin{array}{c}\mathrm{n} \\
{[\mathrm{rpm}]}\end{array}$ & $\begin{array}{c}\mathrm{v} \\
{[\mathrm{km} / \mathrm{h}]}\end{array}$ & $\begin{array}{l}P_{\text {Wheel }} \\
{[\mathrm{kW}]}\end{array}$ & $\begin{array}{l}\mathrm{P}_{\text {Eng }} \\
{[\mathrm{kW}]}\end{array}$ & $\begin{array}{l}\mathrm{P}_{\mathrm{Nomm}} \\
{[\mathrm{kW}]}\end{array}$ & $\begin{array}{l}\mathrm{M}_{\mathrm{Mom}} \\
{[\mathrm{Nm}]}\end{array}$ \\
\hline 1682 & 50,3 & 20,1 & 24,8 & 24,8 & 140,7 \\
\hline 2003 & $59, \overline{9}$ & $2 \overline{6}, \overline{1}$ & 31,8 & 31,9 & $151, \overline{9}$ \\
\hline $2336-$ & $69, \overline{9}$ & 30,8 & 37,6 & 37,6 & $153, \overline{9}$ \\
\hline 2671 & 79,9 & 35,2 & 43,3 & 43,3 & $154, \overline{8}$ \\
\hline 3004 & 89,9 & 38,6 & $48,0^{-}$ & 48,0 & $152, \overline{6}$ \\
\hline 3339 & 99,9 & 41,8 & 52,6 & 52,6 & $150,5^{-1}$ \\
\hline 3673 & $109, \overline{9}$ & 44,1 & 56,5 & 56,5 & 147,0 \\
\hline 4008 & 120,0 & 46,1 & 60,1 & 60,1 & 143,3 \\
\hline 4343 & 130,0 & $4 \overline{7}$ & 62,5 & 62,5 & 137,5 \\
\hline $4 \overline{6} \overline{7}$ & $139, \overline{9}$ & 35,2 & 52,4 & 52,5 & 107,2 \\
\hline
\end{tabular}




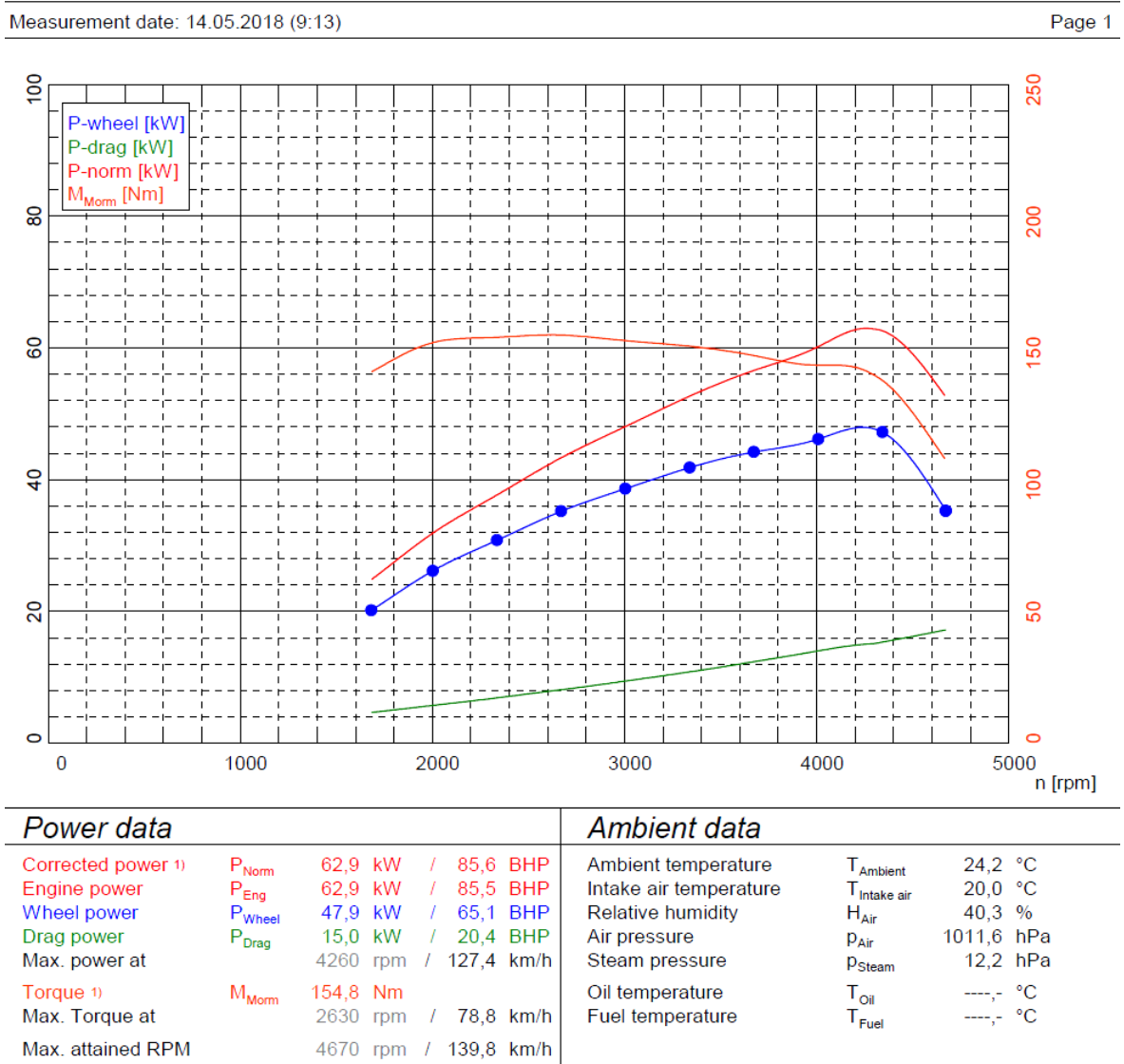

Fig. 5. Characteristics of power and torque for engine discrete measurement.

\section{Conclusion}

Compare the continuous measurement results of vehicles with manually shifted transmission which are based on the standard conditions and have been determined in the nominal engine power range with the target curves. In the nominal torque range discrete measurement is precise. The load dependent losses are included in the adaptation factors of the chassis dynamometer altogether.

Engine combinations tested on a chassis dyno can be done rapidly and data can be evaluated quickly as well. However reliable test data is dependent on many things that any engine builder or vehicle owner should acknowledge and be willing to accept so that they each can learn from the experiences.

\section{References}

1. E. Galindo, D. Blanco, C. J. Brace, E. Chappell, R. Burke, Chassis Dynamometer Testing (SAE, R-452, 2017)

2. S. Rengarajan et al, In-Situ Measurement of Transmission Efficiency in Vehicles, SAE Technical Paper 2017-01-1095, 2017, https://doi.org/10.4271/2017-01-1095

3. S. N. Krivtsov et al 2016 IOP Conf. Ser.: Mater. Sci. Eng. 142012101

4. Bettes H.: A quick view of chassis dynamometer testing, AERA Newsletter, 2010

5. Kołodziej K., Skrzyniowski A.: Badania diagnostyczne samochodów na hamowni podwoziowej AutoDyn 30, Cracow University of Technology, Cracow, 2012 
6. http://rototest-research.eu/index.php?DN=39\&Menu=38\&ID=11

7. The Chassis Dynamometer LPS 3000, Operating Instructions

8. Test Instructions for Engine Power Measurement Chassis Dynamometer: MAHA LPS 3000 